\title{
Trihalomethanes in the Cooling Discharge of a Power Plant on Chlorination of Intake Seawater
}

\author{
R. K. Padhi ${ }^{1 \dagger}$, S. Subramanian ${ }^{1}$, A. K. Mohanty ${ }^{1}$, S. N. Bramha ${ }^{1}$, M. V. R. Prasad $^{1}$, K. K. Satpathy \\ ${ }^{1}$ Environment and Safety Division, Indira Gandhi Centre for Atomic Research, Kalpakkam 603102, Tamil Nadu, India
}

\begin{abstract}
Trihalomethanes (THMs) formation and species distribution in the discharged chlorinated cooling seawater of a nuclear power plant was assessed during Aug 2010 to July 2011. The monthly variation of chlorine demand of the source seawater under laboratory chlorination conditions was studied for the same period. The entire period can be divided into two separate zones; viz. Feb, Mar, Apr, Sep, Oct (low chlorine demand), and May, Jun, Jul, Aug, Nov, Dec, Jan (high chlorine demand) months. Bromoform was found to be the single dominant THMs species in the chlorinated cooling seawater discharge. The THMs concentration was observed to be highest for the month of Nov $2010(41 \mu \mathrm{g} / \mathrm{L})$, and lowest for Feb 2011(12 $\mu \mathrm{g} / \mathrm{L})$. Under laboratory chlorination of intake seawater with 1 ppm $\mathrm{Cl}_{2}$, the concentration of THMs that was formed within 5-15 $\mathrm{min}$ is in agreement with the actual concentration in the discharge water. A simplified predictive approach is proposed for the total THMs concentration at the cooling discharge outlet of a power plant, based on the actual chlorine demand of source water.
\end{abstract}

Keywords: Chlorine demand, Cooling water, Dissolved organic matter, Seawater chlorination, Trihalomethanes

\section{Introduction}

The benefit of using chlorine as a biocide for water treatment has been on serious review after the discovery of trihalomethanes (THMs) in chlorinated water [1]. THMs are a group of four toxic compounds $\left(\mathrm{CHCl}_{3}, \mathrm{CHCl}_{2} \mathrm{Br}, \mathrm{CHClBr}_{2}\right.$, and $\left.\mathrm{CHBr}_{3}\right)$ suspected of causing cancer, liver and kidney damage, retarded foetal growth, birth defects, and possibly miscarriage [2]. THMs, haloketones, haloacetic acids, and haloacetonitrile etc. are the predominant chlorination by-products formed, due to the reaction of chlorine with the organic matter present in the water; and THMs are the major fraction among them. Chlorination to control biofouling in their condenser cooling water system is an important and widely used process adopted by thermal power plants all over the world. A typical nuclear power plant of 1,000 MW(e) capacity uses about $30-45 \mathrm{~m}^{3} / \mathrm{sec}$ of water in its cooling system for effective heat transfer. Seawater is extensively used for this purpose, due to the availability of copious quantity at relatively cheaper rates. Seawater used for once-through condenser cooling is chlorinated at the intake point, i.e., before entering into the cooling conduit; and the chlorinated seawater is discharged back again into the sea. Extensive temporal and spatial variation in the chemical characteristics of seawater causes irregular chlorine demand variations, making it difficult to maintain the desired residual chlorine up to the end of the cooling system outlet. Thus, chlorine demand of the source water needs to be monitored frequently, to avoid over/under chlorination. Further, formation of THMs due to chlorination and mixing of it into the sea raises concern, owing to its toxicity to marine organisms, and consequently to humans through the food chain process.

Chlorination in seawater has features that differ greatly from that of terrestrial waters, due to the phenomenal complexity of the chemical characteristics of seawater. In chlorinated seawater, hypobromous acid ( $\mathrm{HOBr}$ ) is the dominant oxidant species, leading to preferential formation of various brominated by-products, unlike in fresh water systems, where $\mathrm{HOCl}$ is the dominant oxidant species, and the formation of brominated byproducts is negligible. Formation of these THMs in chlorinated seawater needs to be controlled, due to their possible adverse effects on marine organisms [3-5], volatilization of THMs with attendant effects on the atmosphere [6], and permeation into drinking water produced by seawater desalination [7]. Despite recent successes in the exploration of halogenation reactions of terrestrial natural organic matter (NOM) $[8,9]$, the mechanisms and speciation of THM formation in seawater remain to be explored in much detail. Very sparse literature is available on THM formation in cooling water discharge, particularly from Indian coastal waters. Therefore, this research is undertaken to investigate various factors that influence the formation of THM in chlorinated cooling seawater discharge.

The objective of the present study is to investigate the month- (c) This is an Open Access article distributed under the terms of the Creative Commons Attribution Non-Commercial License (http://creativecommons. org/licenses/by-nc/3.0/) which permits unrestricted non-commercial use, distribution, and reproduction in any medium, provided the original work is properly cited.
Received September 10, 2012 Accepted October 08, 2012

${ }^{\dagger}$ Corresponding Author

E-mail: ranjib@igcar.gov.in

Tel: +91-4427480500(23483) Fax: +91-4427480235 


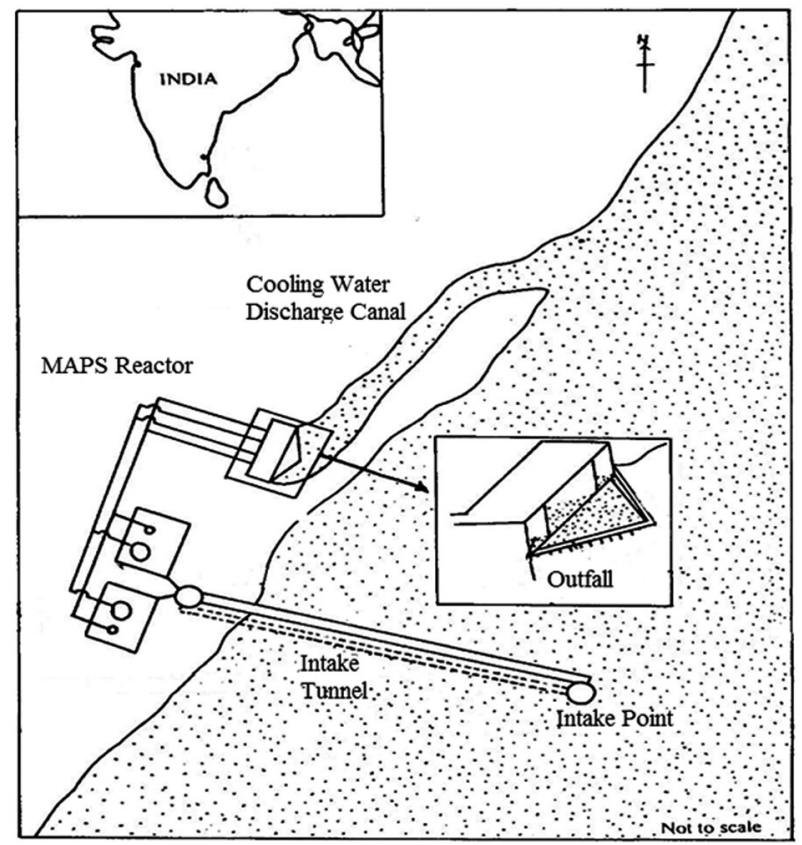

Fig. 1. Study area and sampling location. MAPS: Madras Atomic Power Station.

ly chlorine demand behaviour of the source seawater for the optimisation of chlorine used by power plants, and its relationship with THM formation at the discharge outlet. A simplified predictive approach for the total THMs (TTHMs) concentration at the cooling water discharge outlet of a power plant is proposed.

\section{Materials and Methods}

\subsection{Study Area}

For this study, samples were collected from the discharge water of Madras Atomic Power Station (MAPS), Kalpakkam $\left(12^{\circ} 33^{\prime} \mathrm{N}\right.$; $\left.80^{\circ} 11^{\prime} \mathrm{E}\right)$ located on the Bay of Bengal coast, India. MAPS consists of two pressurized heavy water reactors, and uses approximately $35 \mathrm{~m}^{3} / \mathrm{sec}$ seawater for the once-through cooling system. Seawater drawn for MAPS condenser cooling is chlorinated at the intake point, and the treated water is discharged back to sea through a $500 \mathrm{~m}$ long canal (Fig. 1). Seawater is drawn by gravity through a submarine tunnel of $468 \mathrm{~m}$ long and $3.8 \mathrm{~m}$ diameter, built $53 \mathrm{~m}$ below the seabed. The intake system is such that it takes approximately $5-7 \mathrm{~min}$ for the seawater to travel from the intake to the discharge outfall. Continuous low dose chlorination of about $1 \mathrm{ppm}$ is adopted in this power plant, so as to maintain a residual level of $0.1-0.2 \mathrm{ppm}$ at the discharge outlet. Seawater samples from the MAPS cooling water discharge area were collected once a month. One portion of the samples were treated with excess $\mathrm{Na}_{2} \mathrm{~S}_{2} \mathrm{O}_{3}$ solution to quench the residual chlorine and analyzed on the same day; the other portions were incubated for 5 days before analysis, to obtain maximum TTHM formation potential. Seawater from the intake point that is devoid of any chlorine, and is representative of the ambient seawater used for cooling, was collected simultaneously for blank background value and laboratory chlorination experiments.

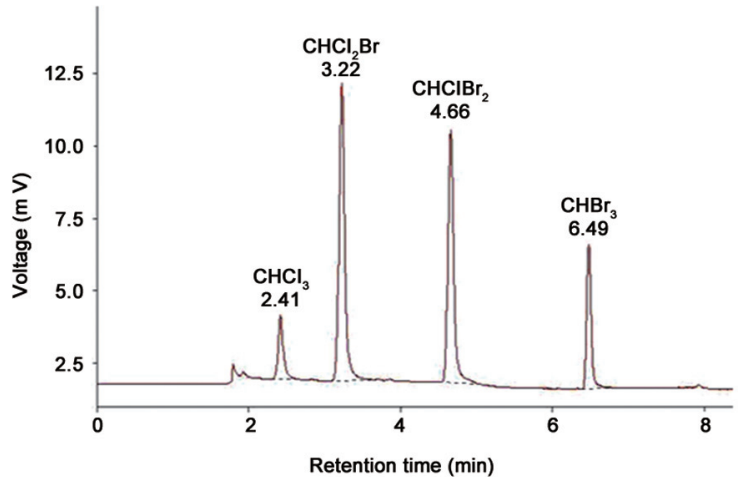

Fig. 2. Pentane extracted chromatogram of $10 \mu \mathrm{g} / \mathrm{L}$ each trihalomethane species.

\subsection{Analytical Methods}

Samples were collected in clean dry glass bottles and brought to the laboratory within $30 \mathrm{~min}$ of collection, and preserved at $4^{\circ} \mathrm{C}$ in the dark until use, to avoid any possible thermal or photo degradation of the organic matter. All glassware used was washed with detergent water, rinsed with tap water, ultrapure water $(18.2 \mathrm{M} \Omega)$, rinsed with acetone and baked at $200^{\circ} \mathrm{C}$ for $2 \mathrm{hr}$, to avoid interference from any volatile contaminants. All chemical and standards used were of high purity, high performance liquid chromatography (HPLC) or gas chromatography (GC) grade. Stock standard solutions of THM mixture were prepared in methanol. Chlorine stock was prepared by dissolving $\mathrm{Ca}(\mathrm{OCl})_{2}$ in Milli-Q water (18.2 M $\Omega$ ), diluted to the required concentration, and standardized by titrimetric method just before use. Chlorine doses of 1 and 3 ppm were added by calculated amount of standardized $\mathrm{Ca}(\mathrm{OCl})_{2}$ solution at various experimental temperatures. Chlorinated samples were taken at different time intervals for analysis of THMs. Before chlorination, seawater was incubated at constant temperature for about $2 \mathrm{hr}$ to equilibrate the water, and constant experimental temperatures were maintained throughout the experiments. Chlorination experiments were carried out both at room temperature and at $40^{\circ} \mathrm{C}$. THM was analyzed with a GC equipped with an electron capture detector, according to the US Environmental Protection Agency (EPA) method 501.2 with some modifications. $100 \mathrm{~mL}$ of sample was extracted with $5 \mathrm{~mL}$ of pentane, and $1 \mu \mathrm{L}$ of extract was introduced to the BPX 50 capillary column for separation and quantification of individual THM species. External reference standards with different concentrations of chloroform $\left(\mathrm{CHCI}_{3}\right)$, bromodichloromethane $\left(\mathrm{CHCl}_{2} \mathrm{Br}\right)$, dibromochloromethane $\left(\mathrm{CHCIBr}_{2}\right)$, and Bromoform $\left(\mathrm{CHBr}_{3}\right)$ were prepared in seawater for calibration and quantification of THMs. The four THMs species, $\mathrm{CHCl}_{3}$, $\mathrm{CHCI}_{2} \mathrm{Br}, \mathrm{CHClBr}_{2}$, and $\mathrm{CHBr}_{3}$ are well resolved under the chromatographic conditions, with retention time of $2.41 \pm 0.02,3.22$ $\pm 0.02,4.66 \pm 0.02,6.49 \pm 0.02 \mathrm{~min}$, respectively, as shown in Fig. 2. The limits and sensitivities of detection for the present instrumental condition is in the following order: $\mathrm{CHCI}_{2} \mathrm{Br}(0.01 \mu \mathrm{g} / \mathrm{L})$, $\mathrm{CHClBr}_{2}(0.01 \mu \mathrm{g} / \mathrm{L}), \mathrm{CHBr}_{3}(0.02 \mu \mathrm{g} / \mathrm{L})$, and $\mathrm{CHCl}_{3}(0.03 \mu \mathrm{g} / \mathrm{L})$.

\section{Results and Discussion}

In this study, concentration distributions of four THM species 


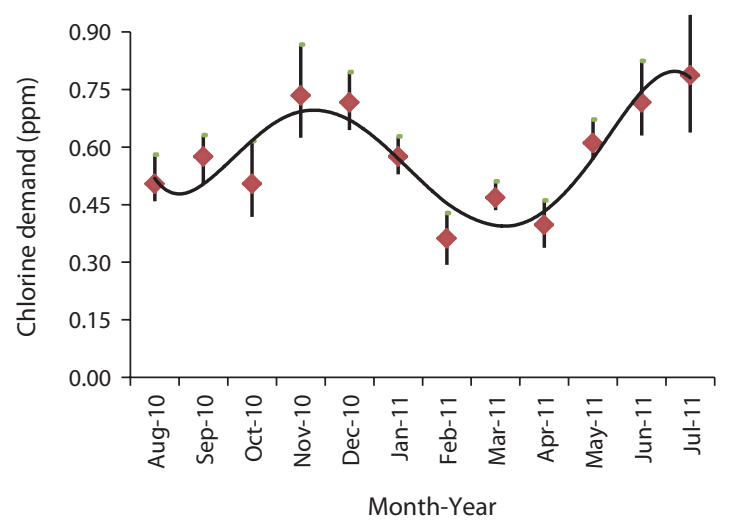

Fig. 3. Monthly chlorine demand variation of seawater for 10 minutes contact time with $1 \mathrm{ppm}$ chlorine dose. Source seawater characteristics; temperature: $25.9-29.9^{\circ} \mathrm{C}, \mathrm{pH}: 7.9-8.2$, and total orgainc carbon: $1.2-1.8 \mathrm{ppm}$.

were determined in the discharge cooling water during Aug 2010 to July 2011. Monthly variation of chlorine demand of the source seawater and formation of THM under various laboratory conditions were studied for the same period. Chlorine demand (10 $\mathrm{min}$ ) of the intake seawater for $1 \mathrm{ppm}$ chlorination at laboratory ambient condition was found to vary between $0.4-0.8 \mathrm{ppm}$ (Fig. 3 ). With respect to the monthly chlorine demand behavior of the seawater, the entire period can be divided into two separate zones; Feb, Mar, Apr, Sep, and Oct as low chlorine demand, and May, Jun, Jul, Aug, Nov, Dec, and Jan as high chlorine demand months. Increase of organic content in the Seawater during the monsoon (Nov-Jan), and enhanced phytoplankton growth during summer (Jun-Jul), might be the reason for experiencing higher chlorine demand during that period. From the result it can be inferred that the practice of low chlorination of about 1 ppm by the power plant under study may be optimum to maintain the desired residual level of $0.1-0.2 \mathrm{ppm}$, for biofouling control during high demand months. However, for lower chlorine demand months, chlorine addition can be further optimized, to reduce over chlorination and by-product formation. The average of TTHM load at the discharge outlet varied between 12-41 $\mu \mathrm{g} / \mathrm{L}$ during the study period, of which bromoform was found to be the main constituent (Fig. 4). 96-98\% of the TTHM formed was observed to be bromoform. Similar observations have been reported by others $[6,10]$ for chlorinated seawater. The dominant formation of bromoform is attributed to the conversion of $\mathrm{Br}$ present in seawater to $\mathrm{HOBr}$, due to the reaction of $\mathrm{HOCl}$ and $\mathrm{Br}$ in water [11].

$$
\begin{aligned}
& \mathrm{Cl}_{2}+\mathrm{H}_{2} \mathrm{O} \quad \leftrightarrow \quad \mathrm{HOCl}+\mathrm{H}^{+}+\mathrm{Cl}^{-} \\
& \mathrm{HOCl}+\mathrm{Br}^{-} \rightarrow \mathrm{HOBr} \quad \text { Rate }_{298}=2.95 \times 10^{3} / \mathrm{sec}
\end{aligned}
$$

Reaction (2) is fast enough to make $99 \%$ conversion of $\mathrm{HOCl}$ to $\mathrm{HOBr}$ in typical seawater of salinity $35 \mathrm{psu}$ in about $10 \mathrm{sec}$ [12]. A few seconds after chlorine addition, this leads to the absence of any $\mathrm{HOCl}$ molecules to coexist with $\mathrm{HOBr}$; ensuing bromine incorporation by the reaction of $\mathrm{HOBr}$ with $\mathrm{NOM}$ as the principal halogenations process. Though bromoform was the only THM formed at the very initial stage on seawater chlorination, higher chlorine dose, longer contact time, and high reaction temperature causes formation of a considerable amount of $\mathrm{CHCl}_{2} \mathrm{Br}$ and $\mathrm{CHClBr}_{2}$. A chlorination experiment was carried out at $40^{\circ} \mathrm{C}$

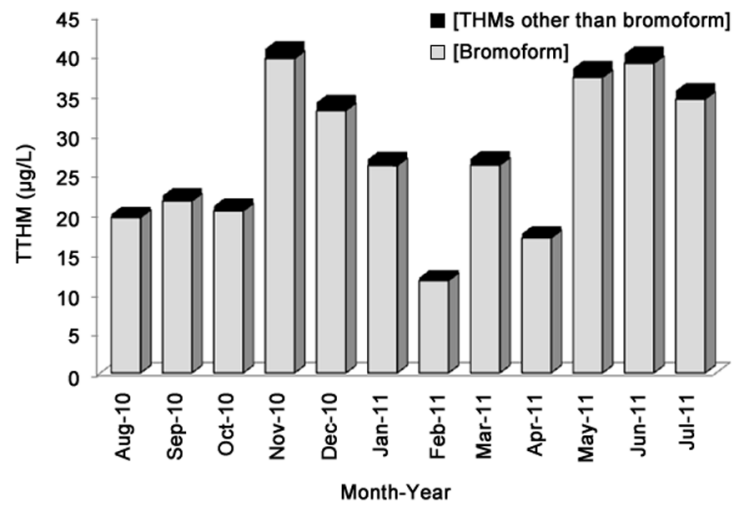

Fig. 4. Monthly total trihalomethane (TTHM) variation at the discharge outlet of Madras Atomic Power Station, Kalpakkam, India.

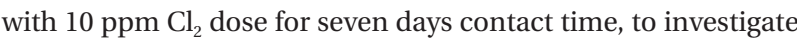
formation of $\mathrm{CHCl}_{2} \mathrm{Br}$ and $\mathrm{CHClBr}_{2}$. A maximum of $1.2 \mu \mathrm{g} / \mathrm{L}$ of $\mathrm{CHCl}_{2} \mathrm{Br}$ and $20.16 \mu \mathrm{g} / \mathrm{L}$ of $\mathrm{CHClBr}_{2}$ were observed during the chlorination experiment, indicating formation of these species at more intense chlorination conditions, though at a very lower rate and concentration compared to $\mathrm{CHBr}_{3}$ formation.

Due to the complexity of seawater, the combined effects of the changes in the complex and heterogeneous water characteristics lead to remarkable temporal and spatial variation in its chlorine consumption efficiency. This makes it extremely difficult to predict the chlorine demand of seawater precisely; and thus empirical studies on the chlorine demand must be made at frequent intervals, to avoid under/over chlorination. Though it is more or less possible to quantify the effects of various operational conditions, viz. $\mathrm{Cl}_{2}$ dose, contact time, temperature, $\mathrm{pH}$, etc., it is exceedingly unlikely to be able to quantify the chlorine reactivity behaviour of numerous unknown complex organic constituents present in the seawater. Moreover, intense qualitative and quantitative site specific variation in the NOM character, and the combined effect of various factors in its reactivity limits the development of any universally acceptable predictive model for chlorine demand and THM formation. NOM variability poses the major limitation in the applicability of various THM prediction models for treated waters [13]. Many studies proposed various complex mathematical models to predict chlorine decay and THM formation in chlorinated cooling and drinking water [14, 15]. But universal applicability of these models is not devoid of uncertainties. In some studies [16, 17], a positive linear correlation of the applied chlorine dose and residual chlorine with THM formation has been suggested for THM prediction. Though concentration dependence of chlorine reactivity induces higher $\mathrm{Cl}_{2}$ demand on increasing chlorine dose, the assumption of linearity in changes of chlorine demand of water with any applied chlorine dose is erroneous. Further, it is theoretically opposite to propose a positive correlation of THM formation with residual chlorine. Chlorine demand, being the source for THM formation, should be the principal component of any mathematical proposition to predict THM formation in chlorinated water.

Here we have proposed a simplified predictive approach for the possible load of THM formation at the discharge outlet of an atomic power station, exclusively taking into account the laboratory chlorine demand of the source seawater. A logarithmic 

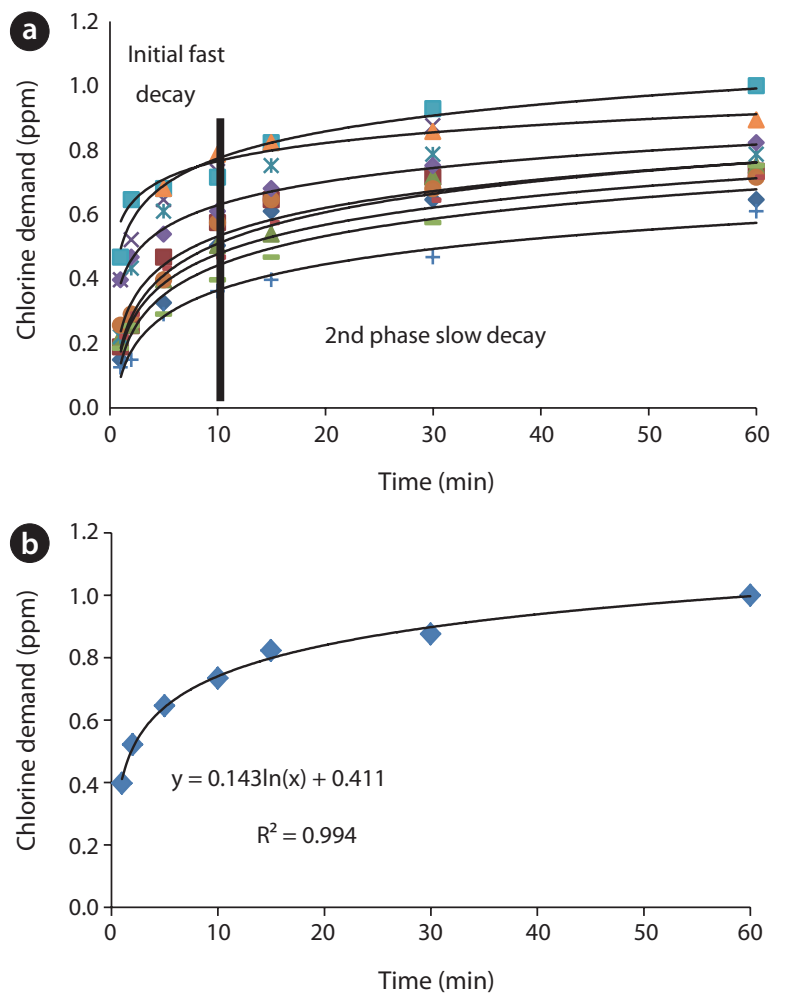

Fig. 5. (a) Logarithmic correlation of time course profile of chlorine demand of seawater taken at various months vs. contact time, and (b) logarithmic R equation for the month of June 2011.

correlation of time course profile of the chlorine demand of seawater taken at various months with time is presented in Fig. 5(a). It has been observed, irrespective of the period of study, that for low level chlorination of a $1 \mathrm{ppm} \mathrm{Cl}_{2}$ dose to the source seawater, the kinetics of chlorine decay showed two distinct phases. The initial phase fast decay of residual chlorine can be referred to as true organic demand, owing to the fast reactive fraction of NOM present in the seawater. The second sluggish continual chlorine demand is attributed to several competitive reactions, including reaction of chlorine with low reacting species, as well as chlorine self-decomposition, and can be referred to as combined chlorine demand. It is generally accepted that the reaction between chlorine and humic substances, a major component of NOM, is responsible for the production of organochlorine compound. Humic and fulvic acids show a high reactivity towards chlorine, and constitute $50-90 \%$ of the total dissolved organic carbon (DOC) in all water systems [18]. The reaction of chlorine with humic acids may lead to a fast reaction rate at first. Other fractions of the DOC comprise the hydrophilic acids (up to $30 \%$ ), carbohydrates $(10 \%)$, simple carboxylic acids $(5 \%)$, and proteins/amino acids (5\%). The reactivity of carbohydrates and carboxylic acids towards chlorine is low, and they are not expected to contribute to the production of organochlorine compounds. Free chlorine reacts with water constituents by three general pathways: oxidation, addition, and substitution [19]. Chlorine can undergo an addition reaction if the organic compound has a double bond. For many compounds with double bonds, this reaction is too slow to be of importance in water treatment. The oxidation reactions with water constituents, such as carbohydrates or fatty acids (e.g., oleic acid), are generally slow. All these slow reacting species result in slow increase in demand and continual formation of THMs occur at a slower rate, even at long after chlorine addition. In addition to applied $\left[\mathrm{Cl}_{2}\right]$, the chlorine demand of raw water mainly depends upon four parameters, namely $\mathrm{pH}$, temperature (T), contact time (t), and the amount of dissolved organic matter present in the water; in other words, chlorine demand can be expressed as:

Chlorine demand $=\mathrm{f}\left(\mathrm{pH}, \mathrm{T}, \mathrm{DOC}, \mathrm{t}, \mathrm{Cl}_{2}\right)$

Multi-parameter power function predictive models are available for THM formation in raw water and treated waters, and in general take the following form $[13,14]$ :

$$
\mathrm{THM}=\mathrm{k}[\mathrm{DOC}]^{\mathrm{a}}[\mathrm{Br}]^{\mathrm{b}}[\mathrm{Temp}]^{\mathrm{c}}\left[\mathrm{Cl}_{2}\right]^{\mathrm{d}}(\mathrm{pH})^{\mathrm{e}}(\mathrm{Time})^{\mathrm{f}}
$$

In other words, the above can be written as:

$$
\mathrm{THM}=\mathrm{f}\left(\mathrm{DOC}, \mathrm{Br}, \mathrm{Temp}, \mathrm{Cl}_{2}, \mathrm{pH}, \text { Time }\right)
$$

In seawater, the bromide content is approximately $65 \mathrm{ppm}$, which is much in excess of the chlorine concentration normally adopted by any power plant for cooling seawater chlorination. Moreover, any minor temporal change in seawater bromide concentration, which may occur, is not supposed to shift the equilibrium or alter the kinetics of Eq. (2). Thus, the contribution of $\mathrm{Br}$ for THM formation for seawater chlorination can be considered constant, and can be appropriately eliminated from the Eq. (4). Again, chlorine demand being a function of all of the other parameters involved, all of these can be replaced with it, and Eq. (5) can be reduced to a single parameter function. On aqueous chlorination, the time course of chlorine decay is always much faster than the comparatively sluggish THM formation. Due to the large difference in their long term time dependence character, a separate time function ( $t$ ) must be included in the time dependence THM prediction formula, and Eq. (5) can be rewritten as:

$$
\mathrm{THM}=\mathrm{f}(\text { Chlorine demand, } \mathrm{t})
$$

The above hypothesis forms the basis for the proposed site specific predictive approach. In the power plant under study, the seawater takes only 5-7 min to travel from the point of chlorination to the discharge outlet. For such a shorter contact time, a separate time factor in Eq. (6) is also not required, and the short term chlorine demand kinetics of source water alone can effectively be used to predict the THM load in the cooling discharge. In the present study, the above hypothesis is tested for its applicability to predict THMs in the cooling discharge water of a nuclear power plant practising short duration (5-7 $\mathrm{min}$ ) low level chlorination of seawater.

The time course profile of chlorine demand for all source seawater samples irrespective of the month of collection fits well to a logarithmical correlation, with $\mathrm{R}^{2}$ values ranging from 0.9191 to 0.9888 . The logarithmic correlation of chlorine demand equation from the graph Fig. 5(b) can be generalised as:

$$
\text { Chlorine demand }=\mathrm{A}+\mathrm{B} * \ln \mathrm{t}
$$

where,

A: The chlorine demand at time $\mathrm{t}=0$ can be taken as the instantaneous chlorine demand responsible for the initial phase kinetics, 


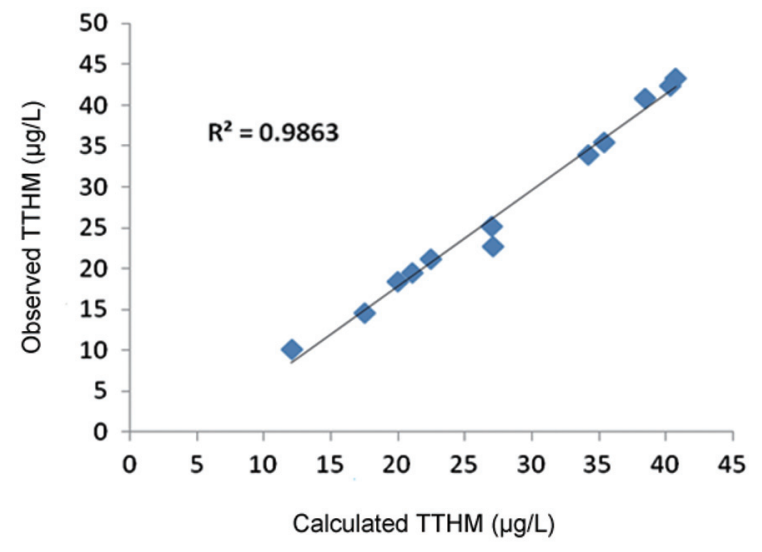

Fig. 6. Linear corelation of observed total trihalomethane (TTHM) at Madras Atomic Power Station discharge area and calculated TTHM using the proposed equation.

referred as to as the true organic demand constant.

$\mathrm{B}$ : The combined chlorine demand constant is the time dependent factor resulting from chlorine consumption through various pathways, including self-decomposition.

$$
\mathrm{B}=\mathrm{B}_{\mathrm{o}}+\mathrm{B}_{\mathrm{n}}
$$

where, $B_{0}$ : the chlorine demand factor for the slow reactive organic fraction, and $\mathrm{B}_{\mathrm{n}}$ : the non-organic chlorine demand.

For low level seawater chlorination of $1 \mathrm{ppm}$, it is observed for the location that the value of ' $\mathrm{A}$ ' varied from 0.09 to 0.41 , but there is a small monthly variation in the combined chlorine demand constant ' $\mathrm{B}$ ', with $\Delta \mathrm{B}_{\max }=0.06$. Therefore, the contribution of the time variable decay factor ' $\mathrm{B} *$ $\ln \mathrm{t}$ ' toward change in the THM formation for a short contact time can be replaced with another constant. Further, since for a shorter contact time, 'A' representing the fast reactive organic fraction of DOC is the major contributor of THM formation, and B comprising organic demand corresponding to the slow relative fraction is mostly due to nonorganic chlorine demand, $B_{n}$ is much greater than $B_{0}$, i.e., $B_{n}>>$ $B_{0}$. Thus, for short time low level chlorination of seawater, formation of THM can be treated as a function of only 'A', and can be mathematically generalized to:

$$
[\mathrm{TTHM}] \alpha \mathrm{A} \rightarrow[\mathrm{TTHM}]=\mathrm{k} * \mathrm{~A}
$$

The value of 'A' for the chlorinated water can be found from the logarithmic correlation equation of chlorine demand vs. time, as in Fig. 5(b).

Substituting the value of ' $k$ ' obtained from linear regression of the values of ' $A$ ' for the number of experimental samples and real samples collected over different stages of study with the observed THM concentration, the above equation becomes:

$$
[\mathrm{TTHM}]=104.45 * \mathrm{~A}
$$

The proposed hypothesis can be used to obtain the ' $\mathrm{k}$ ' values for the source water, to establish its applicability to a similar power plant. The calculated THM concentration using the above equation and observed mean THM concentration in the laboratory chlorination experiments are presented in Fig. 6, and show a very good linear correlation. Though the load of THM formation is known to be dependent on various physicochemical characteristics of water and operational variables, the chlorine demand itself as a function of all independent variables, which contributes solely to THM formation, can be fairly used alone to predict the load of THM formation at the discharge outlet of cooling seawater.

\section{Conclusions}

The chlorine demand of the source seawater needs to be monitored at frequent intervals, to avoid under/over chlorination. The total THM load at the cooling seawater discharge outlet varied between $12-41 \mu \mathrm{g} / \mathrm{L}$, which is well within the stipulated US EPA guideline values of $80 \mu \mathrm{g} / \mathrm{L}$. Bromoform constitutes $96-$ $98 \%$ of the TTHM formed in the chlorinated seawater. Data on the short time course chlorine demand of intake seawater alone can be effectively used to predict the THM concentration at the discharge outlet, with acceptable uncertainties.

\section{Acknowledgments}

The authors express their sincere thanks to Director, IGCAR, Director, EIRSG, and the Asscociate Director, RSEG, for their support and encouragement during the course of this study.

\section{References}

1. Rook JJ. Formation of haloforms during chlorination of natural waters. Water Treat. Exam. 1974;23:234-243.

2. O'Hagan J, Birkinshaw K, Masri M, Therkelsen RL. The formation and fate of trihalomethanes in power plant cooling water systems. Palo Alto: Electric Power Research Institute; 2004. Consultant report no. 500-04-035.

3. Choi DH, Park JS, Hwang CY, Huh SH, Cho BC. Effects of thermal effluents from a power station on bacteria and heterotrophic nanoflagellates in coastal waters. Mar. Ecol. Prog. Ser. 2002;229:1-10.

4. Abarnou A, Miossec L. Chlorinated waters discharged to the marine environment chemistry and environmental impact: an overview. Sci. Total Environ. 1992;126:173-197.

5. Hoepner T, Lattemann S. Chemical impacts from seawater desalination plants: a case study of the northern Red Sea. Desalination 2003;152:133-140.

6. Fogelqvist E, Krysell M. Naturally and anthropogenically produced bromoform in the Kattegat, a semi-enclosed oceanic basin. J. Atmos. Chem. 1991;13:315-324.

7. Dalvi AG, Al-Rasheed R, Javeed MA. Haloacetic acids (HAAs) formation in desalination processes from disinfectants. Desalination 2000;129:261-271.

8. Cowman GA, Singer PC. Effect of bromide ion on haloacetic acid speciation resulting from chlorination and chloramination of aquatic humic substances. Environ. Sci. Technol. 1995;30:16-24.

9. Gallard H, von Gunten U. Chlorination of natural organic matter: kinetics of chlorination and of THM formation. Water Res. 2002;36:65-74.

10. Magara Y, Aizawa T, Kunikane S, et al. The behavior of inorganic constituents and disinfection by products in reverse 
osmosis water desalination process. Water Sci. Technol. 1996;34:141-148.

11. Wong GT, Davidson JA. The fate of chlorine in sea-water. Water Res. 1977;11:971-978.

12. Taylor CJ. The effects of biological fouling control at coastal and estuarine power stations. Mar. Pollut. Bull. 2006;53:3048.

13. US Environmental Protection Agency. Empirically based models for predicting chlorination and ozonation by-products: trihalomethanes haloacetic acids chloral hydrate and bromated. Cincinnati: US Environmental Protection Agency; 1998. EPA no. 815-R-98-005.

14. Sohn J, Amy G, Cho J, Lee Y, Yoon Y. Disinfectant decay and disinfection by-products formation model development: chlorination and ozonation by-products. Water Res. 2004;38:2461-2478.
15. Chang EE, Chiang PC, Chao SH, Lin YL. Relationship between chlorine consumption and chlorination by-products formation for model compounds. Chemosphere 2006;64:11961203.

16. Rajamohan R, Vinnitha E, Venugopalan VP, Narasimhan SV. Chlorination byproducts in the cooling water system of a coastal electric plant. Curr. Sci. 2007;93:1608-1612.

17. Abdel-Wahab A, Khodary A, Bensalah N. Formation of trihalomethanes during seawater chlorination. J. Environ. Prot. 2010;1:456-465.

18. Thurman EM. Organic geochemistry of natural waters. Dordrecht: Kluwer Academic; 1985.

19. Johnson JD, Jensen JN. THM and TOX formation: routes, rates, and precursors. J. Am. Water Works Assoc. 1986;78:156162 . 